\title{
Síndrome Proteus: Contribución a su delineación clínica
}

\author{
Dr. Chrístian Schnake S. ${ }^{1}$, Dr. Leonardo Véjar M.2 , Dra. Margarita Solar B. ${ }^{3}$, \\ Dr. Roberto lbānez C. ${ }^{3}$ Dt. Yves Lacassie S. 4. \\ Proteus syndrome: \\ Contribution to its clinical delineation
}

\begin{abstract}
Proteus syndrome is an apparently rare congenital hamartomatous disorder recently delineated. We report two new cases, one with typical severe phenolype and mental retardation, and the other with moderate asymmetry. macrodactyly and severe cyst like pulmonary abnomalities. These cases corroborate the "polymorphous" characteristics of this syndrome. The current phenotype, based on these two patients and the thirteen cases previously reposted in the world, is presented.

(Key words: Proteus syndrome, hamartomatous disorders, macrodactyly, hemihypertrophy, skull anomalies, cystiform pulmonary anomalies, mental retardation.
\end{abstract}

Wiedemann et $\mathbf{a l}^{\mathbf{1}}$, en 1983 , delinearon, en base a cuatro pacientes, un nuevo síndrome de gigantismo parcial de manos, pies o ambos; nevus; hemihipertrofia; tumores subcutáneos; macrocefalia u otras anomalías del cráneo; posible compromiso visceral $y$ crecimiento exagerado. En tevisiones efectuadas por Gorlin ${ }^{2}$, y por Lezama y Buyse ${ }^{3}$, identifican siete casos aislados descritos previamente. La reciente publicación de dos nuevos $\operatorname{casos}^{4}$, hace llegar a trece los ya descritos. El objetivo de este trabajo es dar a conocer los dos primeros casos diagnosticados en nuestro medio, -uno con alteraciones muy características, y otro con manifestaciones externas discretas, pero con gran compromiso pulmonary contribuir a la delineación de este interesante sindrome.

\section{Casos Clínicas}

1. Paciente de 5 años (F.N. Abril 1981), de sexo masculino, producto de un primer embarazo, hijo de padres sanos, no consanguineos. Después del probando nació un hermano normal. Se desconocen mayores antecedentes familiares. El embarazo cursó con síntomas de aborto du. rante el primer trimestre; el parto fue por

1. Becado de Pediatría, Universidad Católica de Chile.

2. Unidad de Broncopulnonar Infantil, Hospital Sótero del Río.

3. Fisiatra, Instituto de Rehabilitación Infantil de Valparás so (I.R.I.V.).

4. Unidad de Genética, INTA, Universidad de Chile. cesárea, debido a colestasia intrahepática. En el período neonatal se detectaron múltiples malformaciones congénitas, planteándose los diagnósti$\cos$ de: hidrocefalia, neurofibromatosis $y$ Klippel-Trenaunay-Weber (Fig. IA y B). El menor fue abandonado por sus padres y entregado a la custodia de la abuela materna. En varias oportunidades fue hospitalizado pot episodios; bronquiales obstructivos, siendo aún más evidentes sus alteraciones (Fig.1C). Alrededor de $\operatorname{los} 2$ af́os se operó de glaucoma del ojo izqujerdo y, en 1985, se efectó enucleación, por luxación del globo ocular izquierdo. En novjembre de 1985 consulta en el I.R.I.V. A la edad de 5 años (Fig. 2): pesaba $18 \mathrm{~kg}$ (25 a $50 \%$ NCHS); talla $118 \mathrm{~cm}(<95 \%$ NCHS $) ; \mathrm{P} / \mathrm{T}<5 \%$ NCHS; aspecto muy enflaquecido, longilíneo, evidente retraso del desarrollo sicomotor (retardo mental severo). Ctecimiénto global asimétrico con hipertrofia de algunos segmentos localizados, que presentan tumores de tejidos blandos, acumina. dos; cráneo asimétrico, con protuberancias y depresiones, exoftalmo ojo derecho, ojo izquierdo enucleado. Prognatismo, mentón aguzado, altexaciones del esmalte dentario con múltiples caries y úvula ensanchada con tendencia al bifjdismo. Cuello corto, limitación de su movilidad y extensa mancha "café con leche" ligeramente solevantada. Asimetría torácica con deformaciones severas, mancha rojo vinosa en axila derecha, gran mancha hiperpigmentada de superficie rugasa en cara anterior de hemitórax y hemiabdomen derecho. Abdomen asimétrico por adiposidades de la pared. Se palpaba tumoraciones blandas intraabdominales. Dorso: mancha rojo 


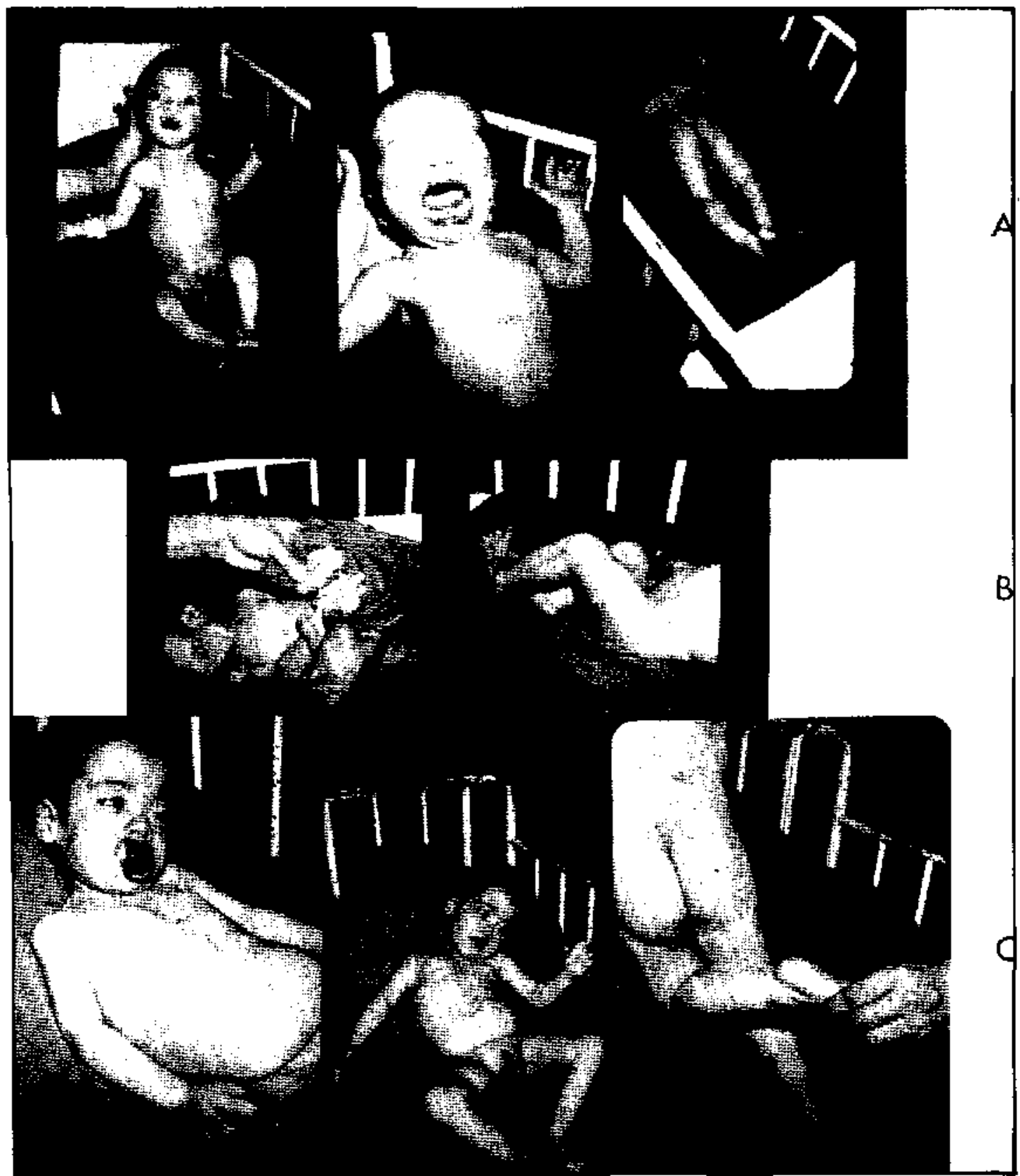

Fig. 1. Caso 1. A y B: en período de recién nacido, apreciándose ya macrodactilia del dedo medio derecho y alteraciones cutáneas. C: durante una de sus hospitalizaciones en período de lactante, siendo cvidente además la alteración ocular a izquierda.

vinosa lumbar acompañada de verrucosidades pigmentadas que se encontraban también en la zona sacrocoxígea, donde habia un pequeño tumor blando pediculado. Genitales: pene con mancha "café con leche" que comprometía su mitad derecha, vello pubiano incipiente. Pies grandes: el derecho medía $20 \mathrm{~cm} \quad(<97 \%$ Feingold y Bossert), el izquierdo $18 \mathrm{~cm}$ (75-97\%), asimétricos, con múltiples tumoracio- nes de consistencia variable, que recordaban, en las plantas, a circunvoluciones cerebrales. Emaciación generalizada de masas musculares en extremidades superiores, asimetría de ambas manos. Mano derecha: palma $9 \mathrm{~cm}(<97 \%)$, dedo medio $8 \mathrm{~cm}(<97 \%)$; pulgar normal, camp to y clinodactilia del indice, macrodactilia marcada del dedo medio y moderada del anular; el meñique y el lado cubital de la palma tenían 


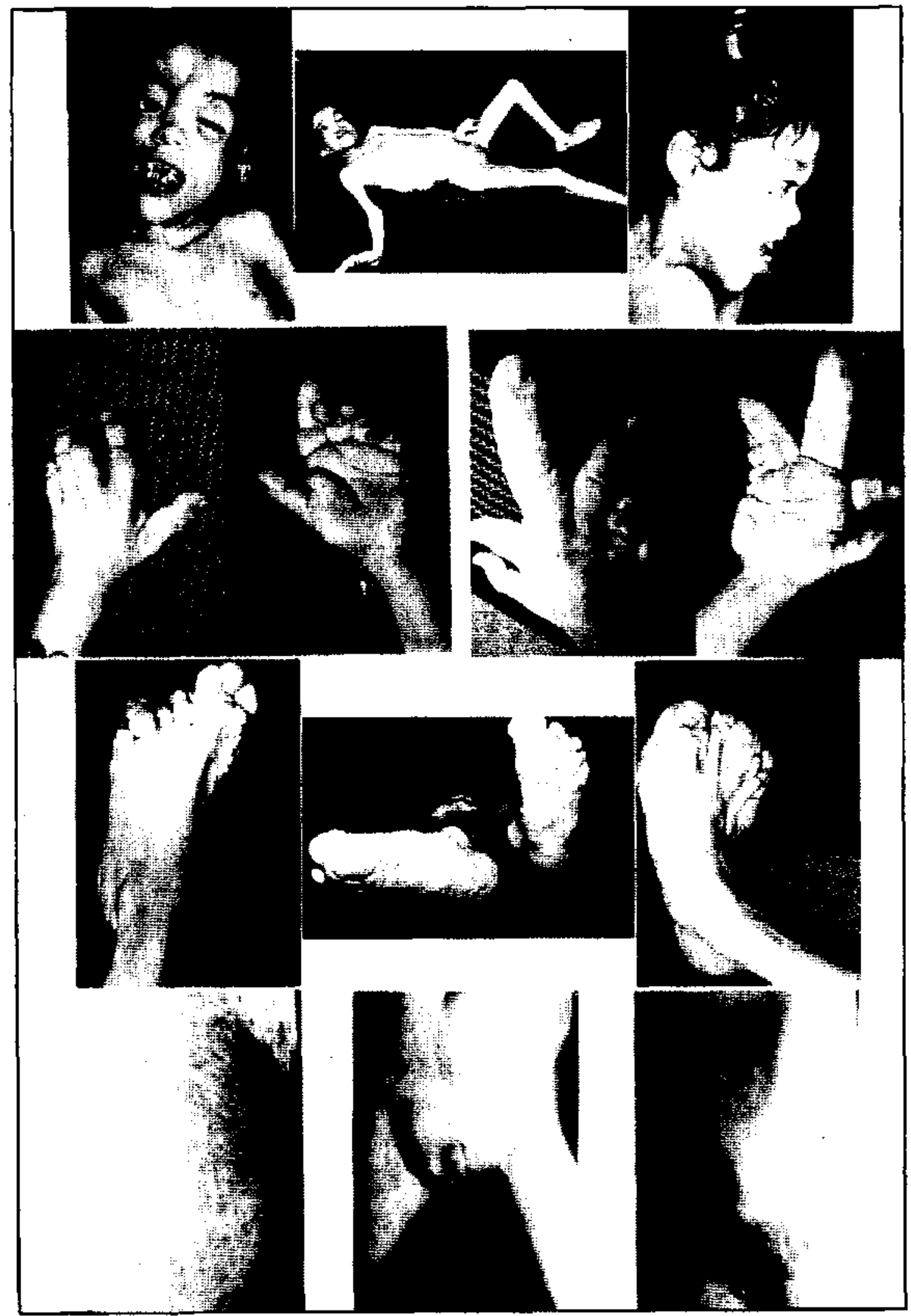

Fig. 2. Caso 1 a los 5 años (ves lexto). 


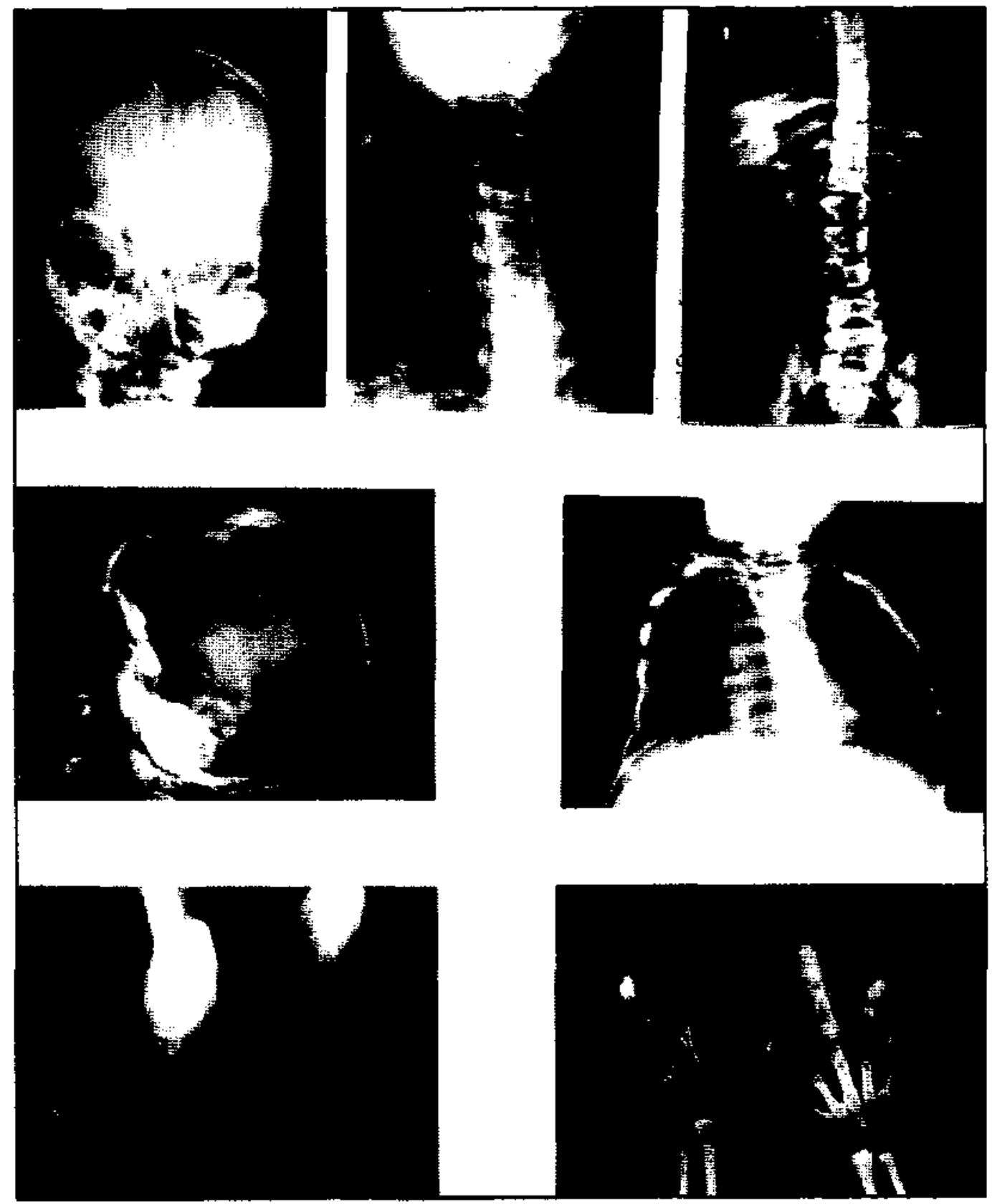

Fig. 3. Estudio radiológion de] caso I (ver texto ).

tejidos redundantes con aspecto de citcunvoluciones que también se veía en la palma, la que presentaba surcos palmares y digitales de flexión marcados Mano izquierda: palma $6,3 \mathrm{~cm}$ (3\%), dedo medio $4,2 \mathrm{~cm} \quad(<3 \%)$; clinodactilid del dedo indice, camptodactilia del dedo medio $y$ discre to aumento de partes blandas en la palma, especialmente en la zona tenar, margen cubital de la zona hipotenar y en la zona de los trirradios basales.

El esțudio radjológico (Fig . 3) mostró dismor- fia cráneo--facial, macrocráneo, aumento de densidad en la base, verticalización del piso anterior, exostosis e hiperostosis en el hueso frontal con evidente asimetría; malformación congénita de vértebras cervicales con tendencia formar bloques; rotoescoliosis de doble seno con deformación y asimetría de los cuerpos vertebrales los que presentaban aumento de la densidad ósea. Pelvis estrecha, tórax asimétrico, calsificación marcada del esternón, imágenes lineales densas del parénquima pulmonar, sin imágenes quísticas. 
Deslizamiento de la cabeza humeral derecha; hipoplasia de tibias y radios; mayor desartollo de radios del pie derecho; pie valgo derecho; macrodactilia de dedos medio y anular derecho, con displasia epifisiaria de segmentos de falanges con formaciones seudoquísticas y aumento notable de partes blandas de aspecto arrosariado.

2. Paciente de 14 años, producto de un cuarto embarazo, de padres sanos, jóvenes (padre 26 , madre 28 afios), no consaguineos, sin antecedentes familiares relevantes. Hermano mayor sano. El segunda hermano falleció a los 5 meses por bronconeumonia. Antes del nacimiento del probando, $y$ en dos oportunidades después de èl, la madre presentó abortos espontáneos de causa no precisada. El embarazo del propósito cursó sin enfermedad; el parto y el período de recién nacido fueron normales, sólo llamó la atención el peso de nacimiento $(5750 \mathrm{~g})$. A los 7 años consultó por crecimiento desmedido e irregular del ortejo mayor izquierdo, que fue corregido mediante exéresis parcial. El estudio anatomopatológico mostró "proliferación de tejido conjuntivo mesenquimático fíbroso laxo que en áreas sufre una transformación hacia cartílago bastante mal formado. Dilataciones sanguíneas, capilares endotelizados. Diagnóstico: mesenquínoma, fibrocondroma". En esa oportunidad se constató escoliosis cérvico-dorsal de concavidad derecha, asimetría torácica, pequeña mancha con aspecto de hemangioma en indice y pulgar derechos, e imágenes aisladas de tipo quístico en la base pulmonar derecha, sin alteraciones aparentes de la función respiratoria, siendo catalogado como un síndrome de Klippel-Trenaunay-Weber. No se controló hasta Noyiembre de 1985: en que consultó por disnea progresiva en los últimos cuatro años, que lo obligó a abandonar sus estudios, a pesar de tener buen rendimiento, y lo limitaba a una mínima actividad física. En el examen de ingreso tenía cianosis, disnea ante esfuerzos mínimos, taquicardia, enflaquecimiento, (talla $160 \mathrm{~cm}$ ( $50 \%$ NCHS), peso $39 \mathrm{~kg}$ ( 5 a $10 \%$ NCHS), circunferencia craneana $55 \mathrm{~cm}(50 \%$ Nellhaus), y disfonia. En el examen segmentario (Fig. 4) había asimetría de cráneo y cara, con mayor prominencia del lado derecho; paladar alto; una mancha café con leche en mejilla derecha; cuello corto con marcada limitación para la rotación y extensión; tórax hiperexpandido, asimétrico, prominencia del hemi-tórax derecho, marcada xifo-escoliosis dorsal dextrocóncava, disminución acentuada del murmullo vesicular, que estaba prấcticamente abolido en el pulmón derecho, latido de ventrículo derecho palpable; genitales pequeños; asimetría de extremidades inferiores; la pierna izquierda era $2 \mathrm{~cm}$ más larga que la derecha; pies asimétricos, el derecho medía $24,8 \mathrm{~cm}$ ( 25 a $50 \%$ ), el izquierdo $26,9 \mathrm{~cm}$ ( 75 a $90 \%$ ), ortejo mayor izquierdo con crecimiento exagerado, superficie irregular con aspecto de circunvoluciones, lo que era menos notorio en el segundo y tercer ortejos; manos con muy discreta asimetría: palma derecha $9,9 \mathrm{~cm}$ (25 a $50 \%$ ), dedo medio $6,9 \mathrm{~cm}$ ( 3 a $25 \%$ ), palma izquierda $9,5 \mathrm{~cm}$ ( 3 a $25 \%$ ), dedo medio $6,9 \mathrm{~cm}$ (3 a 25\%); dos manchas rojo vinoso en dorso de mano derecha sobre el primer y segundo metacarpiano; acortamiento de cuartos metacarpianos; asa con bolsa radial en el anular derecho. Examen neurológico e intelectual normales. El estudio radiológico pulmonat incluyó radiografía simple de tórax, planigrafía de ventilación $y$ perfusión y tomografía axial computarizada. (Fig. 5). Estos exámenes revelaron gran destrucción del parénquima pulmonar, marcado atra. pamiento de aire, múltiples bulas de gran tamaño, hiperinsufladas, fenómeno más acentuado en el pulmón derecho; perfusión de radiofármaco muy irregular, especialmente disminuida en esa misma zona, ventilación prácticamente inexistente en ella, compatible con una alteración mixta de perfusión e inhalación en ambos campos pulmonares, con mayor compromiso del pulmón derecho. Pielografía de eliminación, ultrasonografía hepática y renal y estudio con doppler de cabeza y extremidades fueron normales. El estudio radiológico de esqueleto demostró asimetría cráneofacial, alteración morfológica de todas las vértebras cervicales, con asimetría, tendencia a bloque $\mathrm{y}$ rotación, hipoplasia de $\mathrm{C} 4 \mathrm{y}$ C5 y deformación de C6 y $\mathrm{C7}$, xifoescoliosis dextro-cóncava, por hemivértebra $y$ fusión vertebral, angulación anormal de los radios, acortamiento de los cuartos metacarpianos, discreto acortamiento de la tibia derecha, crecimiento exagerado de los falanges, especialmente distales, del primer, segundo y tercer ortejo izquierdos. Los exámenes de función respiratoria demostraron limitacion ventilatoria de predominio obstructivo, extrema, no modificable; marcado aumento de la gradiente alvéolo-arterial que no aumentaba en ejercicio, con hipoxemia severa; hipoventilación alveolax crónica que aumentaba en ejercicio y limitación marcada de la fuerza muscular inspiratoria. El tratamiento esteroidal de prueba, con $1 \mathrm{mg} \times \mathrm{kg}$ al día de Prednisona durante 10 días, no modificó las pruebas funcionales. Otros exámenes de laboratorio como: prueba del sudor, baciloscopias, cultivos de bacilo de Koch, factor reumatoídeo, anticuerpos antinucleares, complemento $\mathrm{C} 3$ e Inmunoglobulinas plasmáticas fueron normales. Las hemogramas demostraron poliglobulia y trombocitopenia leve; el electrocardiograma sobrecarga de cavidades derechas; el estudio de expectoración 


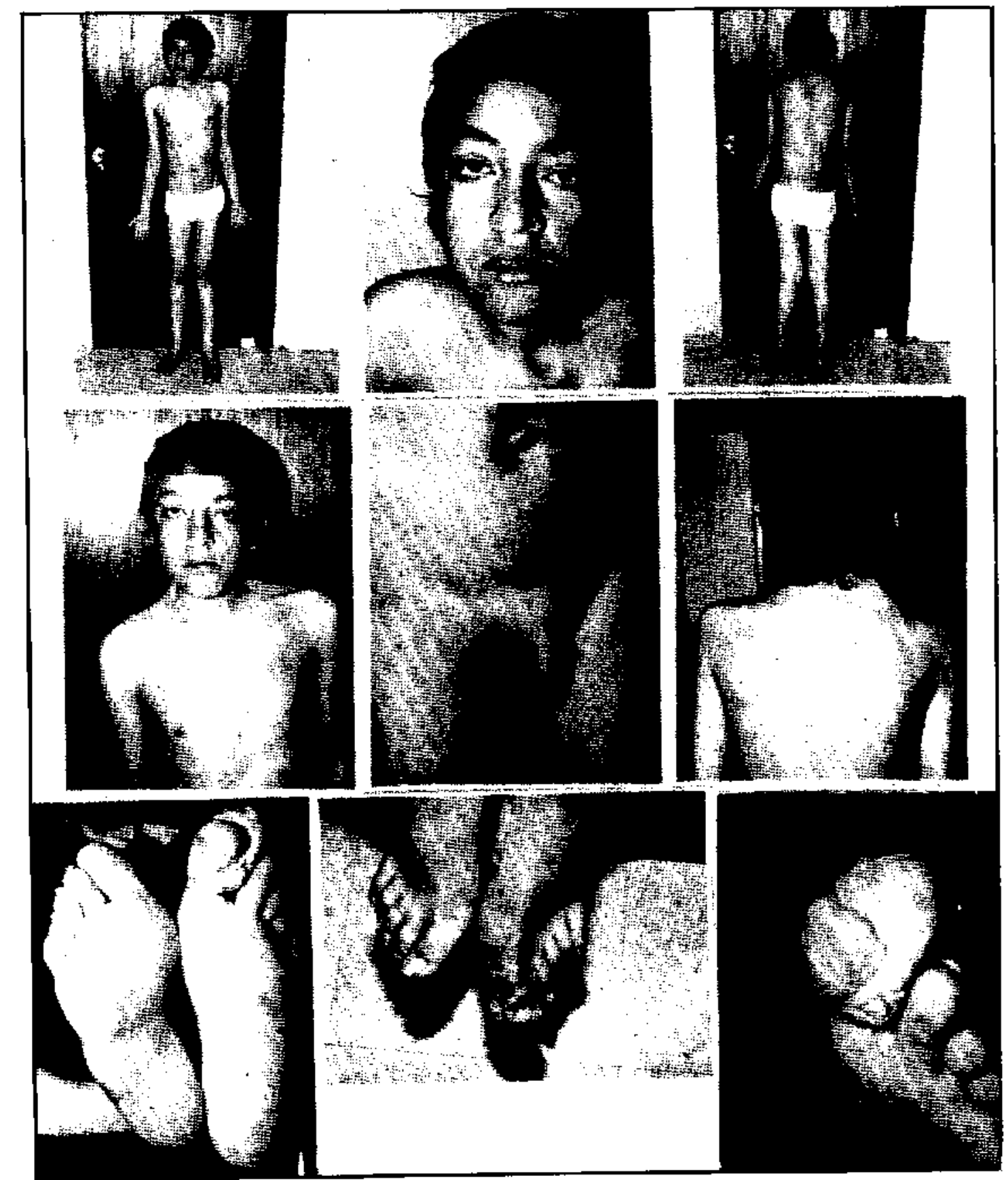

Fig. 4. Caso 2 a los 14 años (ver texto).

hemosiderófagos abundantes, con evidencjas de eritro y leucofagia en varias muestras.

\section{DISCUSION}

Con los dos pacientes descritos, el número de casos, con aparente síndrome Proteus, publicados hasta la fecha, alcanza a quince ${ }^{1-5}$. Recientemente un nuevo caso ha sido diagnosticado ${ }^{6}$. Un resumen de las características fenotípicas de nuestros dos casos y de los trece previos, se presenta en la Tabla 1. Aunque los porcentajes con que se presentan las diferentes características fenotípicas varian a medida que se describen nuevos casos, por el momen1o, las únicas características constantes $(100 \%)$, serían el crecimiento asimétrico con hipertrofia del esqueleto y e] engrosamiento de la piel y tejido subcutáneo que dan el aspecto característico, giriforme, observado en estos pacientes. 


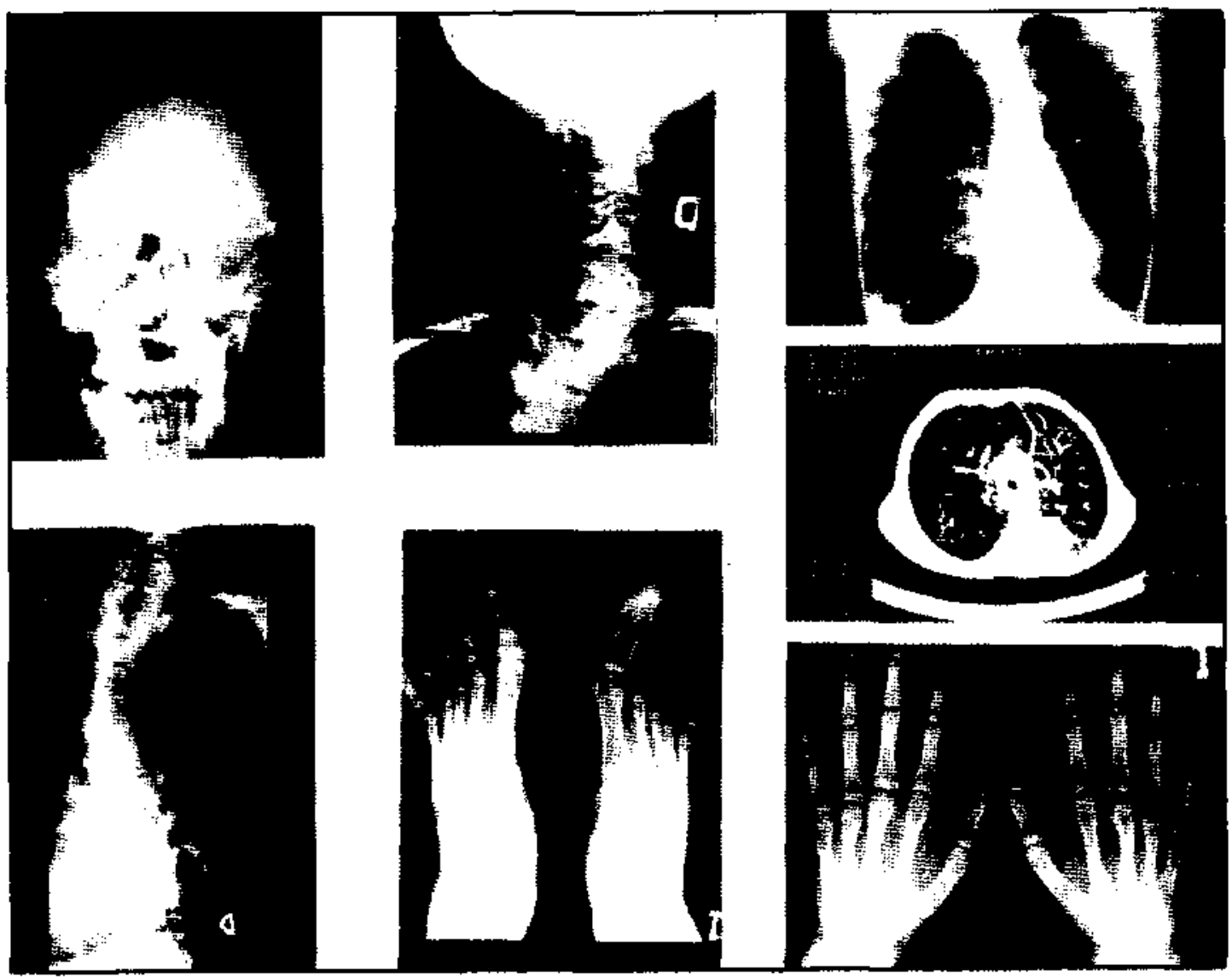

Fin. 5. Y itudio radiológico de] caso 2 (vert texto).

Con frecueticia el crecimien to exagerado pro. duce localmente macrodactilia (93\%) y acentuaria el délicit ponderal $(80 \%)$ magnificado por la atrofia muscular $(78 \%)$. La presencia de nevus epidérmicos $(86 \%)$ y masas subcutáneas inespecíficas $(73 \%$ son también frecuentes. Es posible que la lipomatosis pelvica presente en los dos casos de Costa ${ }^{4}$ y evidente en el caso 1, esté subestimada porque hasta el momentu no ha sido investigada en foma sistemática.

Desgraciadamente, como en muchos otros síndromes genéticos, no hay marcadores independientes del fenotipo que permitan establecer el diagnóstico. Nuestros dos casos ilustran la gran variabilidad fenotipica del sindrome, que es lo que motivó a Wiedemann y cols. ${ }^{1}$, a proponer el têrmino Proteus (e] "polimorfo" dios griego) para esta condición.

El defecto básico pareciera ser un crecimiento exagerado, localizado, de elementos celulares en piel, hueso y otros tejidos conectivos. Las características clínicas en cada paciente depender del sitio afectado. Todas las manifestaciones presen1cs en el $100 \%$ de los casos, contribuyen al crecimiento notablemente asimétrico en estc sindrome. Nunque el crecimiento abcrrante puede afectar cualquier estructura, pudiendo producir desde unjo asimetría facial moderada ${ }^{1}$, presente en el caso 2, hasta agrandamiento masivo de una extremidad ${ }^{3,4}$, esta afección tiene unia predileceión por munos y pies, con macrodactilia evidente en el 93\%. Invariablemente está asociado con hipertrolía esquelética $y$ con frecuencia a crecimien to exagerado de tejidos blan. dos. En aquetlos casos en que se ha hecho biopsia se ha encontrado tejido normal, fibromas. neurofibromas, hamastomas y con mayor frecuencia tejido adiposo ${ }^{3-4}$. En el caso 2 la biopsia del ortejo mayor sugirió un me senquimoma y fibrotondroma. Ninguno de los casos de $\operatorname{Costa}^{4} 0$ revisaldos por ella tenían alteraciones histológicas en el hueso hipertrofiado. Es de interés el alto peso de nacimiento del caso 2 , descrito también en uno de los casos originales de Wiedemann ${ }^{1}$ y en otros dos casos ${ }^{3}$ sin una explicación patogénica. Las prominencias óseas del cráneo han sido descritas como hiperustosis o exostosis, aunque pudieran representar osteomas ${ }^{4}$. En nuestros dos pacientes estaban presentes, siendo cvidente la mayor densidad ósea observada tam- 
Tabla I.

Caracteristicas fenotipicas del Sínd rome Proteus (ad aptado de Costa ét al. 4 ,

\begin{tabular}{|c|c|c|c|c|}
\hline Manifestaciones & $\begin{array}{c}\text { interatura } \\
\text { (N) }\end{array}$ & Caso 1 & Caso 2 & $\operatorname{lotal}(\%)$ \\
\hline \multicolumn{5}{|l|}{ CRECIMIFNTO } \\
\hline Asimetría & $13 / 13$ & + & + & 100 \\
\hline Macrodactilja & $12 / 13$ & + & + & 93 \\
\hline - Sistatura aumentada & $7 / 11$ & + & & 62 \\
\hline -- Peso disminuido & $6 / 8$ & + & + & 80 \\
\hline Macrocefaliat & $4 / 7$ & + & - & 56 \\
\hline \multicolumn{5}{|l|}{$\overline{\text { PILIL }}$} \\
\hline - Nevus epidérmico & $10 ; 12$ & + & + & 86 \\
\hline $\begin{array}{l}\text { J: ngrosamiento de fa piel y } \\
\text { tejido subcutálseo }\end{array}$ & & & & \\
\hline - Despigmentación & $\begin{array}{r}12 ? 12 \\
3,13\end{array}$ & + & $\begin{array}{l}+ \\
-\end{array}$ & 20 \\
\hline Manchas calé con leche & $1 / 12$ & + & + & 21 \\
\hline Lesiones pigmentad as inespecif. & $1 / 13$ & + & & 13 \\
\hline - Lipoma tosis & $5 / 11$ & + & & 46 \\
\hline - Anomalias vasculares & $8 / 13$ & + & + & 67 \\
\hline - Masas subcutáncas ine specificar & $10 / 13$ & + & - & 73 \\
\hline \multicolumn{5}{|l|}{ FSQUE:LI:TO } \\
\hline - Prominencias óscas del cráneo & $9 / 13$ & + & + & 73 \\
\hline - Anotualías vertebraies & & + & + & $2 / 2$ \\
\hline - Hipertrofia & $13 / 13$ & + & + & 100 \\
\hline - Escoliosis, xifosis & $4 / 13$ & + & + & 40 \\
\hline - Pectum excayatuIn & $2 / 13$ & .- & & 13 \\
\hline- Anquilosis de los codos & $3 / 1,3$ & - & - & 20 \\
\hline - Angulación defectuosa de las rodilias & $6 / 7$ & - & - & 67 \\
\hline \multicolumn{5}{|l|}{ OJOS } \\
\hline Frstrabisno & $5 / 13$ & + & & 40 \\
\hline - Tumor epibulbar & $3 / 13$ & - & - & 20 \\
\hline - Agrandamiento ocular & $2 / 13$ & + & -- & 20 \\
\hline Miopia avanzada & $2 / 13$ & & . & 13 \\
\hline Catarala & $1 / 13$ & & - & 7 \\
\hline Nistagmus & $1 / 13$ & & - & 7 \\
\hline Ptosis & $1 / 13$ & & & 7 \\
\hline - Glaucomat & & + & & $1 / 2$ \\
\hline - Luxación ocular & & + & & $1 / 2$ \\
\hline \multicolumn{5}{|l|}{ OTROS } \\
\hline - Retardo mental & $6 ! 13$ & + & - & 46 \\
\hline - Convulwiones & $2 / 13$ & - & - & 13 \\
\hline - Anomalias pulmonares & $4 / 11$ & & + & 38 \\
\hline - Atrofï muscular & $5 / 7$ & + & + & 78 \\
\hline Lipomatosis pélvica & $2 / 2$ & + & & 75 \\
\hline
\end{tabular}

bién en otros huesos. La presencia de otros hamartomas, especialmentc vasculares, también ha sido descrita. En cuatro de once pacientes publicados se han descrito anomalías pulmona. res. Uno tenía neumonitis aspirativas crónicas desarrollando una enfermedad pulmonar restrictiva. En la autopsia se encontró que tenśa uñ hamartoma mixto mesénquimo-bronqujal en el lóbulo superior derecho. Otro tenia evidencias de obstrucción mecánica al flujo aéreo, con radio- grafía de tórax anormal: y dos, cortespondientes a los casos originales de Wiedemann, tenían anomalías quísticas de los pulmones, que llevaron a uno de ellos a una disnea progresiva de reposo y sobreinfecciones frecuentes. Esto es similar a lo observado en nuestro caso 2 , cn el cual ya a los siete años se observaban anomalias quísticas, aún sin alteración funcional respiratoria. Es posible que al buscar en formla dirigida e] compromiso pulmonar, éstc sca más frecuente de 
lo que actualmente se piensa.

Entre los diagnósticos diferenciales hay que considerar las hamartosis y otras afecciones que pueden producir macrodactilia ${ }^{7,8}$, o alguno de los otros signos destacados. Las hamartosis que presentarian mayor similitud $y$ que han sido consideradas en los diagnósticos diferenciales son los síndromes de Bannayan, de KlippelTrenaunay-Weber, de Maffuci, de Ollier $y$ de Riley-Smith, la neurofribromatosis, los nevus epidérmicos y los nevus cebáceos lineales. Aunque la diferenciación entre algunos de ellos, como neurofibromatosis $y$ síndromes de Bannayan, a veces pueder ser difícil ${ }^{9}$, las manifestaciones clínicas del sindrome Proteus aparecen como tan distintas de las otras hamartosis que no debiera haber confusión. Sin embargo, cabe la posibilidad de que algunos ejemplos de hamartosis pobremente delineadas, como el Kippel-Trenaunay-Weber y otras, pudieran en realidad representar formas incompletas de este sindrome. De hecho, algunos casos publicados con ese diagnóstico han sido retrospectivamente diagnosticados como Proteus ${ }^{4}$. En ambos casos, en algún momento, se planteó dicho diagnóstico.

La historia natural del sindrome Proteus aún no se conoce debido al reducido núme to de casos descritos y a que el mayor de los pacientes sólo tenía 24 años. No cabe dudas del curso progresivo pero variable de esta afección. Algunos pacientes presentan manifestaciones ya al nacer. pero en la mayoría de los casos el comienzo ha sido en el primer año de vida. El caso l (Fig. I y 2) ilustra la evolución desde recién nacido hasta los 5 años de sus diferentes alteraciones; algunas, como la macrodactilia $y$ defectos de pigmenta. ción estaban presentes ya al nacer. En el caso 2 fue imposible precisar el momento en que comenzó el crecimiento exagerado del ortejo mayor izquierdo, siendo aparentemente normal al nacer. El pronóstico a largo plazo tampoco se conoce por las razones mencionadas. Hay un caso que falleció a los 11 años en el post-operatorio de una fusión vertebral. Esto nos hace pensar que las malformaciones vertebrales, presentes en nuestros dos casos y no destacadas hasta el momento ${ }^{1-5}$, pudieran constituir una manifestación relevante. Si bien la principal preocupación pronóstica la constituye el riesgo de desarrollar neoplasias como en otras hamartosis. creemos que los problemas respiratorios, cono lo observado en el caso 2 , pueden constituirse en un factor invalidante y limitante de sus expectativas de vida. El retraso mental descrito en casi la mitad de los casos, evidente, aunque no objetivado en el paciente 1 , junto a la luxación oculat que obligó a su enucleación, seríat otras manifestaciones limitantes.
La causa del síndrome Proteus es desconocida. Su naturaleza progresiva y el compromiso multisistémico permiten plantear una etiología genética ${ }^{1-4}$. Todos los casos descritos han sido aislados, con historias familiares regativas, como sucede en nuestros casos. Las padres, hermanos y un hijo de los pacientes descritos han sido nomales. Aunque la relación de sexos ha sido descrita como no significativamente diferente, la mayoria de los pacientes descritos han sido hombres ${ }^{4}$. Como sucede con la mayoría de las hamartosis, es posible una herencia autosómica dominante en que los pacientes presentarían una nueva mutación. La edad paterna avanzada descrita en alguno de los casos sugiere esta posibilidad ${ }^{1,3-5}$ Los estudios cromosómicos realizados en sangre y fib roblastos han sido nomales ${ }^{1}$. El determinar exactamente el tipo de herencia es de importancia fundamental para el consejo genético.

\section{RESUMEN}

El sindrome Proteus es una hamartosis congénita, aparentemente poco frecuente, delineada recientemente. Se describen dos casos, uno con un fenotipo grave $y$ característico, incluyendo retardo mental, y otro con asimetría moderada, macrodactilia y anomalías pulmonares quísticas graves. Estos casos corroboran la característica "polimórfica" de este síndrome. Basado en estos dos pacientes y en los trece publicados en el mundo, se analiza su fenotipo y aspectos más relevantes.

\section{AGRADECIMIENTOS}

Se agradece al Departamento de Respiratorio del Hospital Clínico de la Pontificicia Universidad Católica de Chile la colaboración prestada para el estudio del Caso 2. Al Dr. Carlos Vildósoli la evaluación radiológica de ambos pacientes. A la Dra. Rosa Corvo por haber facilitado las fotografías de recién nacido y lactante del Caso 1. Al Dr. Roberto Gorlin por habernos enviado dos artículos no obtenibles en Chile.

\section{REFERENCIAS}

1. Wiedemann, H.R., Burgio, G.R., Aldenhoff. P., Kunze, J., Kaufmann, H.J., Schirg, E.: The Proteus Syndrome. I:ur. J, Pediatr, 140: 5, 1983.

2. Gorlin, R.J.: Proteus Syndrome, J. Clin. Dysmorph. 2: 8,1984 .

3. Lezama, $D$ B., Buyse, M.L.: The Proteus Synd tome: The emergency of an entity. J. Clin. Dysmorph. 2: 10,1984 . 
4. Costa, T, Fitch, N, Azouz, E.M.: Proteus syndrome: Report of two cases with pelvic lipomatosis. Pediatrics 76: $984,1985$.

5. Temtamy, S.A., Rogers, J.G.: Macrodactyly, hemihypertrophy, and connective tissue nevi: Report of a new syndrome and review of the literature. J. Pedia1t. B9: 924, 1976.

6. Gorlin, R.J.: Comnicación personal. Abril, 1986.

7. Smith. D.W.: Recognizable patterns of human mal- formation. Third Edition. W.B. Saunders Co., Philadelphin, 1982 .

8. Temtamy. S.A, McKustck, $V .:$ The genetics of hand malformations. Brith Defects Original Article Series, Vol. XIV, No 3, A.R. Liss Inc., New York, 1978.

9. Lacassie, Y.: Sindrome de múltiples lipomas, hemangiomas y macrocefalia: una expresión de neurofibromatosis. Arch. Biol. Med. Exp. 15: 65(A), 1981 . 